\title{
Simulation analysis of common mode voltage suppression strategies for PWM inverter
}

\author{
Wang xinsheng ${ }^{\mathrm{a},{ }^{*}}$, Cheng guorui ${ }^{\mathrm{b}}$ \\ Information and Electrical Engineering college, Harbin Institute of Technology at Weihai, Weihai, \\ China \\ awangxswh@126.com, ${ }^{\mathrm{b}}$ cgrhit@163.com
}

Keywords: Inverters, Common mode voltage suppression, Matlab/Simulink simulation.

\begin{abstract}
With the development of power electronics technology and devices, PWM inverter has been widely used and its fundamental principles have become a new chapter in power electronics course. Three-phase PWM inverter is an important part of motor drive system, the output voltage is composed of differential mode voltage and common mode voltage. The power is transmitted on the basis of differential mode voltage. The current generated by the common mode voltage will consume unfavorable power when it flows through load. However, the impact and analysis of common mode voltage has not attracted enough attention in the teaching of power electronics compared to differential mode voltage. In this paper, software method is used to study the effect of the suppression strategies of common mode voltage. The basic idea is to improve the modulation algorithm and the control of the non zero vector. The traditional SVPWM modulation strategy and several SVPWM based non zero vector PWM (NZPWM) strategies are compared, and then implemented in MATLAB/SIMULINK environment. Finally, the suppression effect on common mode voltage of different strategies is analyzed.
\end{abstract}

\section{Introduction}

Three-phase PWM inverter is an important part of the motor drive system [1].It's output voltage includes differential mode voltage and common mode voltage. The former is the component that exists between the two phase output of the inverter, and the latter is the component of the inverter output to the ground. With the increasing of the switching frequency of the PWM inverter, when the output has a high-frequency characteristic and a rapidly rising common mode voltage acts on the asynchronous motor, the characteristics of the high-amplitude voltage pulse have a great influence on the performance of the asynchronous motor [2].

The modulation strategy of PWM inverter can be improved by changing the state combination of inverter devices. It is a software method to suppress the common mode voltage of the inverter. This method does not change the topology of the system and does not increase the cost of hardware. It is the main direction of the inverter common mode voltage suppression. In this paper, we first analyzes the principle and algorithm implementation of traditional space vector pulse width modulation (SVPWM) [3] strategy, then gives several non zero vector pulse width modulation (NZPWM) [4] strategy based on SVPWM, their principle and method are analyzed and studied.

\section{Several modulation strategies to suppress common mode voltage}

\subsection{SVPWM modulation strategy}

In the electric traction AC drive system, most of the asynchronous motors are powered by a three-phase two-level PWM inverter [5]. There are eight operating modes for the PWM inverter. For each effective working state, the phase voltage is represented by a synthetic space vector, which is one of the $\overrightarrow{U_{0}} \sim \overrightarrow{U_{7}}$. These vectors have equal amplitude and different phase. The switch vectors of mode 0 and mode 7 are zero vectors. 
We can insert some linear combinations in the original interval $\overrightarrow{U_{1}} \sim \overrightarrow{U_{2}}$, which is an example to illustrate the implementation of SVPWM control. The linear combination of the new voltage space vector $\overrightarrow{U_{r e f}}$ is shown in Figure 1, where $T_{s}$ is the action time of $\overrightarrow{U_{r e f}}$.

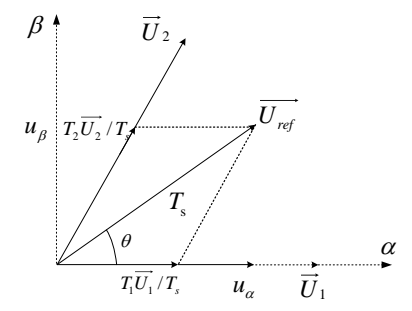

Fig. 1. Linear combination of voltage space vector

The $T_{1}$ and $T_{2}$ in Figure 1 can be calculated according to the following equations:

$$
\int_{0}^{T_{s}} \overrightarrow{U_{r e f}} d t=\int_{0}^{T_{1}} \overrightarrow{U_{1}} d t+\int_{T_{1}}^{T_{1}+T_{2}} \overrightarrow{U_{2}} d t+\int_{T_{1}+T_{2}}^{T_{s}} \overrightarrow{U_{0}} d t
$$

However, the common mode voltage peak output by the PWM inverter in the zero vector state is 3 times of the non zero vector state. If do not use zero vectors, use other non zero vectors instead of zero vectors, or non zero vectors was used to synthesize the reference vector by a new way. This modulation is called non zero vector pulse width modulation (NZPWM).

\subsection{Different NZPWM modulation principles}

The modulation vector relations of RSPWM, AZSPWM1, AZSPWM3 and NSPWM are shown in Figure 2.

The RSPWM [6] modulation strategy mainly has 3 kinds of switch states, and the three switch states differ from each other in space by 120 degrees. We use the different combinations of fixed vector groups $\overrightarrow{U_{1}}, \overrightarrow{U_{3}}$ and $\overrightarrow{U_{5}}$ (or $\overrightarrow{U_{2}}, \overrightarrow{U_{4}}$ and $\overrightarrow{U_{6}}$ ) to synthesize reference voltage $\overrightarrow{U_{\text {ref }}}$, as shown in Figure 2(a), instead of using zero vectors. The AZSPWM1 [7,8] modulation strategy uses two non zero vectors of equal size and opposite direction to replace zero vector in SVPWM modulation, which not only has the same effect as zero vector, but also suppresses the output common mode voltage. In addition to using the two non zero vectors involved in the synthesis of the reference vector $\overrightarrow{U_{r e f}}$, the AZSPWM1 modulation strategy also uses the remaining two non zero vectors that are not on the same axis as the two non zero vectors to replace the zero vector. For example, the selection of the voltage space vector in sector I is shown in figure 2(b). The NSPWM mainly describes the reference voltage through three near voltage vectors. For example, in the first sector, $\overrightarrow{U_{1}}, \overrightarrow{U_{2}}$, and $\overrightarrow{U_{3}}$ are used to represent the reference voltage, as shown in figure 2 (c). AZSPWM3 is similar to NSPWM, it also uses three voltage state vectors to describe the reference voltage. The difference is Which voltage vectors are referenced. For example, in the first sector, NSPWM is mainly described by $\overrightarrow{U_{1}}, \overrightarrow{U_{2}}$, and $\overrightarrow{U_{3}}$, while AZSPWM3 is mainly described by $\overrightarrow{U_{1}}$, $\overrightarrow{U_{2}}$, and $\overrightarrow{U_{4}}$, as shown in figure $2(\mathrm{~d})$.

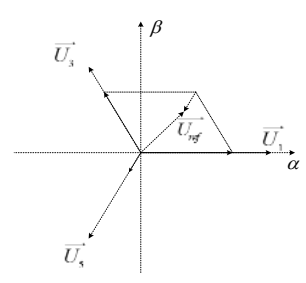

(a)RSPWM

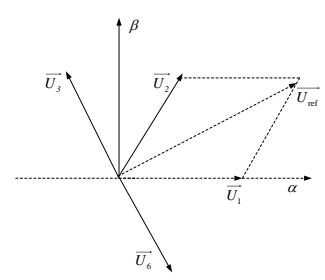

(b)AZSPWM1

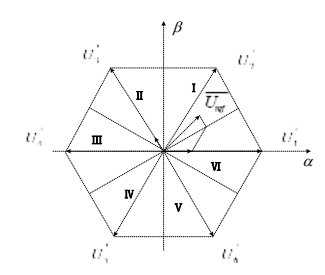

(c)NSPWM

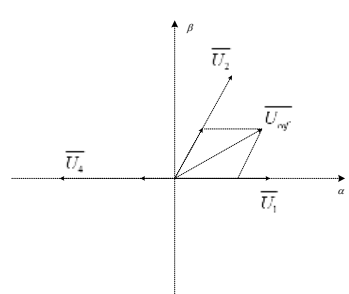

(d) AZSPWM3

Fig. 2. Space vector diagram of different NZPWM

According to the principle of volt-second balance, the product of the reference voltage vector $\overrightarrow{U_{r e f}}$ and the switching period $T_{s}$ is equal to the cumulative sum of the products of the voltage state 
vectors and their active time. Therefore, according to this principle, the calculation formula of the voltage state vector action time for different NZPWM can be calculated.

Assuming a certain modulation factor, it is defined as:

$$
m=\sqrt{3} U_{r e f} / U_{d} .
$$

If the RSPWM modulation strategy uses the voltage vectors $\overrightarrow{U_{1}}, \overrightarrow{U_{3}}, \overrightarrow{U_{5}}$ to synthesize the reference voltage, the calculatin formula for the action time of each voltage vector is:

$$
\left\{\begin{array}{l}
T_{3}=T_{s} / 3+m T_{s} \sin (\theta-\pi / 3) / \sqrt{3} \\
T_{5}=T_{s} / 3-m T_{s} \sin (\theta+\pi / 6) / \sqrt{3} \\
T_{1}=T_{s}-T_{3}-T_{5}
\end{array}\right.
$$

In the formula, $T_{1}, T_{3}$, and $T_{5}$ are the action times of $\overrightarrow{U_{1}}, \overrightarrow{U_{3}}$, and $\overrightarrow{U_{5}}$, respectively. $(0 \leq \theta \leq \pi / 3)$

For the AZSPWM1 modulation strategy, in the first sector, the action time of each voltage vector is:

$$
\left\{\begin{array}{l}
T_{1}=T_{s} m \sin (\pi / 3-\theta) \\
T_{2}=T_{s} m \sin \theta \\
T_{0}=T_{s}-T_{1}-T_{2}=T_{s} m \sin (\pi / 3+\theta)
\end{array}\right.
$$

In the formula, $T_{1}$ and $T_{2}$ are the action time of vector $\overrightarrow{U_{1}}$ and $\overrightarrow{U_{2}}$ respectively, the action time of vector $\overrightarrow{U_{3}}$ and $\overrightarrow{U_{6}}$ are equal, all are $T_{0} / 2 .(0 \leq \theta \leq \pi / 3)$

For the AZSPWM3 modulation strategy, in the first sector, the action time of each voltage vector is:

$$
\left\{\begin{array}{l}
T_{1}=\sqrt{3} T_{s} m \sin (\theta+5 \pi / 6) / 2+T_{s} / 2 \\
T_{2}=T_{s} m \sin \theta \\
T_{4}=T_{s}-T_{1}-T_{2}=T_{s} / 2-T_{s} m \sin (\theta+\pi / 3) / 2
\end{array}\right.
$$

In the formula, $T_{1}, T_{2}$, and $T_{4}$ are the time of action of vector $\overrightarrow{U_{1}}, \overrightarrow{U_{2}}$ and $\overrightarrow{U_{4}}$ respectively. $(0 \leq \theta \leq \pi / 3)$

For the NSPWM modulation strategy, in the first sector, the action time of each voltage vector is:

$$
\left\{\begin{array}{l}
T_{2}=\sqrt{3} T_{s} m \sin (\pi / 6+\theta)-T_{s} \\
T_{3}=T_{s}-T_{s} m \sin (\theta+\pi / 3) \\
T_{1}=T_{s}-T_{2}-T_{3}=T_{s}-T_{s} m \sin \theta
\end{array}\right.
$$

In the formula, $T_{1}, T_{2}$, and $T_{3}$ are the time of action of vector $\overrightarrow{U_{1}}, \overrightarrow{U_{2}}$ and $\overrightarrow{U_{3}}$ respectively. $(\pi / 6 \leq \theta \leq \pi / 2)$

\section{Simulation Implementation of modulation strategies}

According to the principle of SVPWM algorithm, it's algorithm implementation is mainly divided into voltage transformation, sector estimation, action time calculation, switching time calculation and pulse modulation.

\subsection{Voltage transformation}

Three-phase coordinate transformation to two-phase $\alpha-\beta$ coordinates:

$$
\left[\begin{array}{l}
u_{\alpha}(t) \\
u_{\beta}(t)
\end{array}\right]=\sqrt{\frac{2}{3}}\left[\begin{array}{ccc}
1 & -\frac{1}{2} & -\frac{1}{2} \\
0 & \frac{\sqrt{3}}{2} & -\frac{\sqrt{3}}{2}
\end{array}\right]\left[\begin{array}{l}
u_{A}(t) \\
u_{B}(t) \\
u_{C}(t)
\end{array}\right]
$$




\subsection{Determine the which sector the reference voltage vector $\overrightarrow{U_{\text {ref }}}$ is located}

The basic voltage space vector for this switching period is determined by determining which sector the voltage space vector $\overrightarrow{U_{r e f}}$ is located. Use $u_{a}$ and $u_{\beta}$ to represent the component of reference voltage vector on the $\alpha$ and $\beta$ axes, respectively, and define three variables $U_{\text {refl }}, U_{\text {ref } 2}$ and $U_{\text {ref } 3}$ :

$$
\left\{\begin{array}{l}
U_{\text {ref } 1}=u_{\beta} \\
U_{\text {ref } 2}=\sqrt{3} u_{\alpha}-u_{\beta} \\
U_{\text {ref } 3}=-\sqrt{3} u_{\alpha}-u_{\beta}
\end{array}\right.
$$

Then three variables, $\gamma, \delta$, and $\varepsilon$, can be obtained by analysis.

If $U_{\text {refl } 1}>0$, then $\gamma=1$, otherwise $\gamma=0$;

If $U_{\text {ref2 } 2}>0$, then $\delta=1$, otherwise $\delta=0$;

If $U_{\text {ref } 3}>0$, then $\varepsilon=1$, otherwise $\varepsilon=0$.

Define $\zeta=4 * \varepsilon+2 * \delta+\gamma$, the relationship between the $\zeta$ and the sector can be obtained, and the which sector $\overrightarrow{U_{\text {ref }}}$ is located can be obtained through table 1 .

Table 1. The corresponding relationship between $\zeta$ and sector

\begin{tabular}{|c|c|c|c|c|c|c|}
\hline$\zeta$ & 3 & 1 & 5 & 4 & 6 & 2 \\
\hline Sector & I & II & III & IV & V & VI \\
\hline
\end{tabular}

\subsection{Determine the action time of two near non zero vectors and zero vectors in each sector}

The action time of two near non zero vectors in different sectors can be summed up to the calculation of $\eta, \lambda$ and $\mu$ :

$$
\left\{\begin{array}{l}
\eta=\frac{\sqrt{3} T_{s} u_{\beta}}{U_{d}} \\
\lambda=\frac{\sqrt{3} T_{s}}{U_{d}}\left(\frac{\sqrt{3}}{2} u_{\alpha}+u_{\beta} / 2\right) \\
\mu=\frac{\sqrt{3} T_{s}}{U_{d}}\left(-\frac{\sqrt{3}}{2} u_{\alpha}+u_{\beta} / 2\right)
\end{array}\right.
$$

\subsection{Determine the vector switching points in each sector}

Define three interval times, as shown in formula (9):

$$
\left\{\begin{array}{l}
T_{a}=\left(T_{s}-T_{1}-T_{2}\right) / 4 \\
T_{b}=T_{a}+T_{1} / 2 \\
T_{c}=T_{b}+T_{2} / 2
\end{array}\right.
$$

The relationship between the three-phase voltage switching time switching points Tcmp1, Tcmp2, Tcmp3 and each sector is shown in Table 2.

Table 2. The switching time of Tcmp1、Tcmp2、Tcmp3 every sector

\begin{tabular}{|c|c|c|c|c|c|c|}
\hline$\zeta$ & 1 & 2 & 3 & 4 & 5 & 6 \\
\hline $\mathrm{T}_{\text {cmp1 }}$ & $\mathrm{T}_{\mathrm{b}}$ & $\mathrm{T}_{\mathrm{a}}$ & $\mathrm{T}_{\mathrm{a}}$ & $\mathrm{T}_{\mathrm{c}}$ & $\mathrm{T}_{\mathrm{c}}$ & $\mathrm{T}_{\mathrm{b}}$ \\
\hline $\mathrm{T}_{\text {cmp2 }}$ & $\mathrm{T}_{\mathrm{a}}$ & $\mathrm{T}_{\mathrm{c}}$ & $\mathrm{T}_{\mathrm{b}}$ & $\mathrm{T}_{\mathrm{b}}$ & $\mathrm{T}_{\mathrm{a}}$ & $\mathrm{T}_{\mathrm{c}}$ \\
\hline $\mathrm{T}_{\text {cmp3 }}$ & $\mathrm{T}_{\mathrm{c}}$ & $\mathrm{T}_{\mathrm{b}}$ & $\mathrm{T}_{\mathrm{c}}$ & $\mathrm{T}_{\mathrm{a}}$ & $\mathrm{T}_{\mathrm{b}}$ & $\mathrm{T}_{\mathrm{a}}$ \\
\hline
\end{tabular}

The modules such as coordinate transformation, sector estimation, vector action time calculation, switching time calculation and pulse modulation module are built in MATLAB/SIMULINK environment, as shown in Figure 3. 


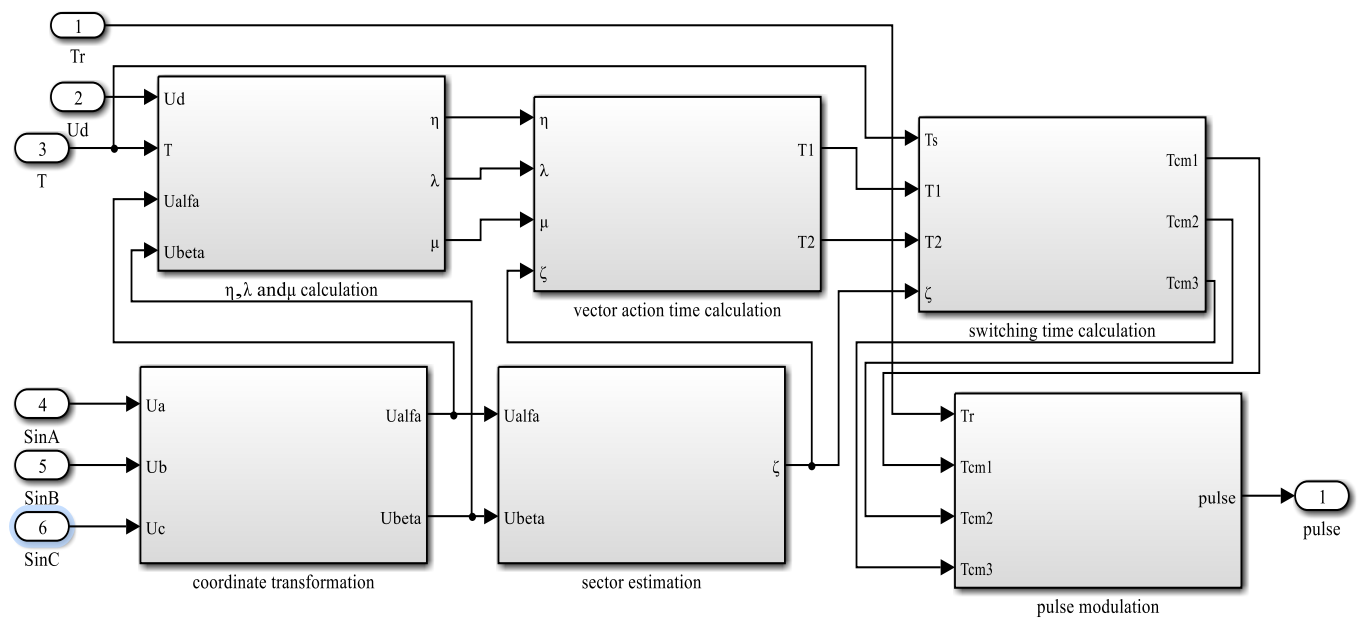

Fig. 3. Simulation model of modulation pulse generation subsystem

\section{Simulation results}

The driver system model simulation circuit based on the SVPWM modulation strategy is shown in Figure 4. IGBT is used as a power device to form a three phase full bridge inverter circuit [9]. Motor stator winding is simulated by resistance series inductance of star connection. The neutral point is recorded as $\mathrm{N}$, and the common mode voltage is $\mathrm{N}$ point to ground voltage. The specific simulation parameters are as follows: DC bus voltage $U_{d}=600 \mathrm{~V}$, sampling period $T_{s}=0.0001 \mathrm{~s}$, inverter output frequency $50 \mathrm{~Hz}$, resistance $\mathrm{R}=5 \Omega$, inductor $\mathrm{L}=0.001 \mathrm{H}$. In addition, a triangular wave is used as a carrier, its period is $T_{s}$, and its amplitude is $T_{s} / 2$.

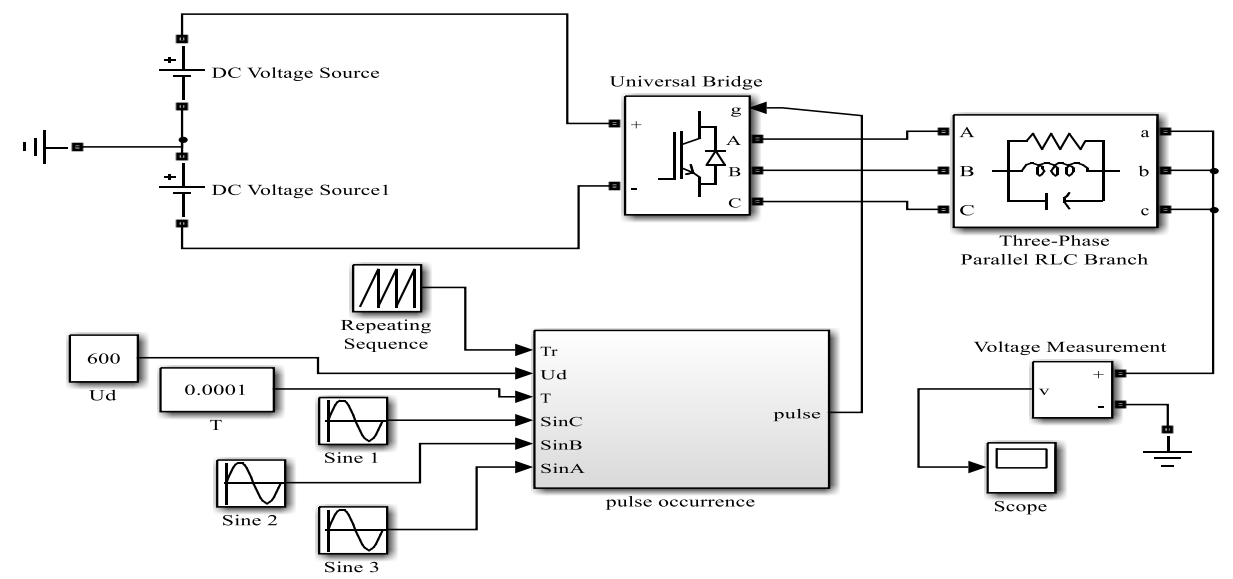

Fig. 4. Simulation model of motor drive system

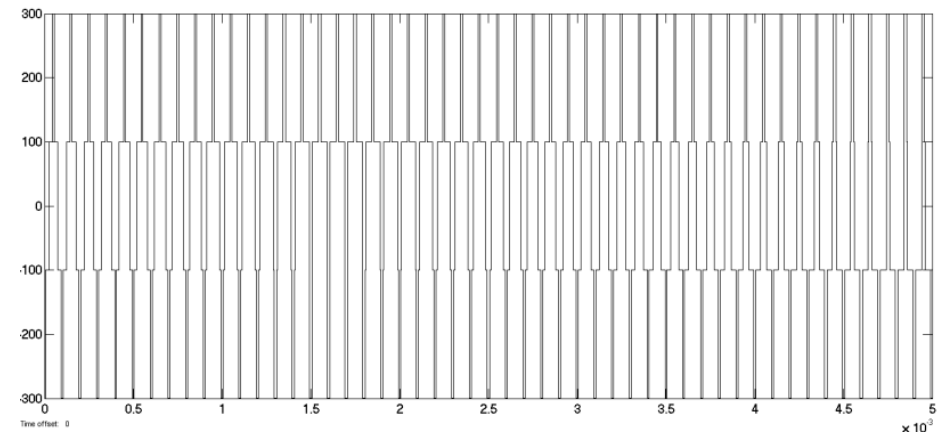

Fig.5. Common mode voltage waveform in SVPWM modulation strategy

When the SVPWM modulation strategy is adopted, the output common mode voltage can not be eliminated fundamentally by any kind of switch sequence. The common mode voltage waveform of 
SVPWM modulation is shown in Figure 5. It is seen from the diagram, the common mode voltage of the SVPWM modulation strategy has two amplitude levels, $300 \mathrm{~V}\left(U_{d} / 2\right)$ and $100 \mathrm{~V}\left(U_{d} / 6\right)$ respectively. The simulation results are in accordance with the theoretical analysis.

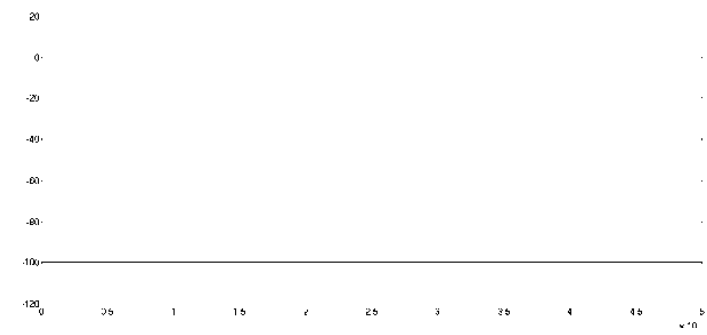

(a)RSPWM

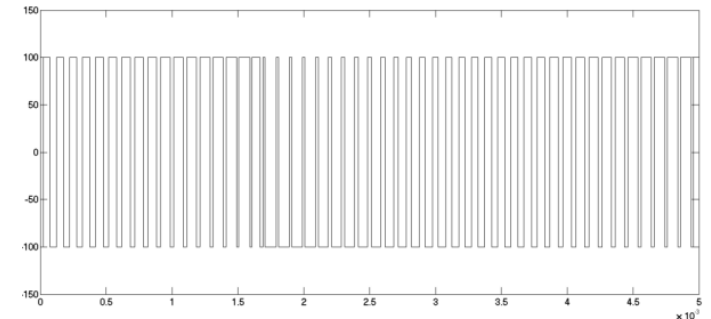

(c)AZSPWM3

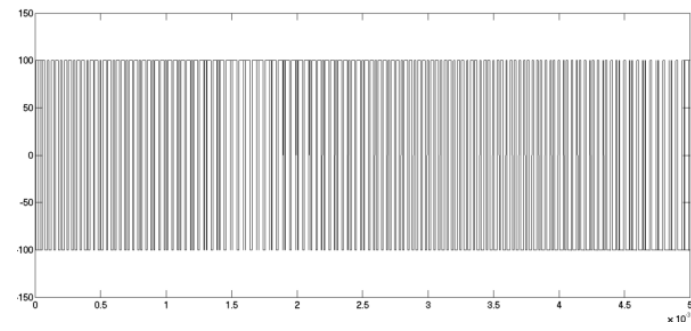

(b)AZSPWM1

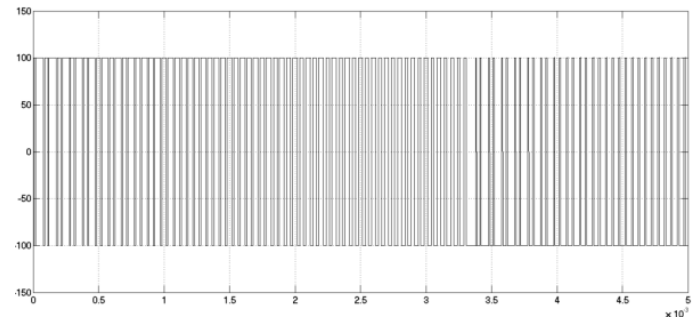

(d)NSPWM

Fig. 6. Common mode voltage waveform in NZPWM modulation strategy

Since the RSPWM modulation strategy uses fixed vector groups $\overrightarrow{U_{1}}, \overrightarrow{U_{3}}$ and $\overrightarrow{U_{5}}$ to describe the reference voltage, and the corresponding common mode voltage amplitude is $-U_{d} / 6$. Therefore the common mode voltage value in the RSPWM modulation strategy is always $-100 \mathrm{~V}$. The common mode voltage amplitude $+U_{d} / 6$ alternates with $-U_{d} / 6$ at AZSPWM1, AZSPWM3, and NSPWM modulation strategies, that is $+100 \mathrm{~V}$ and $-100 \mathrm{~V}$ are appeared alternately. It turns out that the common mode voltage is effectively suppressed. Simulation results in line with theoretical analysis.

\section{Conclusion}

In this paper, PWM inverter drive motor system common mode voltage suppression methods are studied. The traditional SVPWM modulation strategy and several NZSPWM modulation strategy that are based on SVPWM are compared. The simulation results show that NSPWM modulation strategy effectively suppress the common mode voltage compared to differential mode voltage. For this paper, we simply study several software suppression methods. In the future, we can study the existing research methods in depth and also combine the hardware suppression methods.

\section{Acknowledgement}

This work was supported partially by Shandong Provincial Natural Science Foundation, China (Project No.ZR2017MEE053). The authors greatly appreciate the financial support.

\section{References}

[1] ZHAO Jianyong, PAN Zaiping, LU Huifang, REN Lu,ZhANG Binchun, Construction of Innovative Experiment Platform for Single Phase Inverter System, Laboratory Research and Exploration, vol. 36, pp. 196-199, 2017.

[2] JIANG Yanshu, LIU Yu, XU Dianguo, ZHAO Hong, Research on Common-mode Voltage Generated By a PWM Inventer and Its Cancellation Technology, Chinese Society for Electrical Engineering, vol. 25, pp. 47-53, 2005. 
[3] HUANG Jin, XIONG Rui, WANG Zhi, ZUO Wenping, ZOU Yunping, SPWM Control Strategy to Reduce Inverter Common-Mode Interferences Based on Three-Phase Four-Leg Structure, IEEE on Industrial Electronics And Applications, pp. 924-928, 2008.

[4] LU Haifeng, QU Wenlong, ZHANG Xing, FAN Yang, CHENG Xiaomeng, Asymmetrical NZPWM technique for reducing the common-mode voltage, Journal of Tsinghua University (Science and Technology), vol. 47, pp. 1122-1125, (1129), 2007.

[5] ZHANG Yihai, The Research on Common-mode Voltage about The System of Driving Asynchronous Motor by PWM-Inventer[D], Chengdu: Southwest Jiao Tong University, 2014.

[6] XU Jie, NIE Ziling, ZHU Junjie, ZHANG Yinfeng, LI Huayu, Restudy on the Random Pulse Width Modulation, Electric Machines \& Control Application, vol. 43, pp. 45-51, 2016.

[7] ZHANG Xing, WANG Tiancheng, WANG Fusheng, REN Kangle, An Improved Reduced Common-mode Voltage Pulse Width Modulation Strategy, Power Electronics, vol. 49, pp. 89-92, 2015.

[8] KANG Qiang, Analysis and Suppression of Common-Mode Voltage in PWM Varid Frequency Supply Power System[D], Beijing: Beijing Jiaotong University, 2016.

[9] CHEN Jingxi. Study on PWM Induction-motor VVVF Speed Regulation System[D], Huazhong University of Science and Technology, 2007. 